\title{
Mitochondrial Dysfunction in Neurodegenerative Diseases
}

\author{
Ashu Johri and M. Flint Beal \\ Department of Neurology and Neuroscience, Weill Medical College of Cornell University and New York Presbyterian Hospital, \\ New York, New York
}

Received February 4, 2012; accepted June 1, 2012

\begin{abstract}
Neurodegenerative diseases are a large group of disabling disorders of the nervous system, characterized by the relative selective death of neuronal subtypes. In most cases, there is overwhelming evidence of impaired mitochondrial function as a causative factor in these diseases. More recently, evidence has emerged for impaired mitochondrial dynamics (shape, size,
\end{abstract}

fission-fusion, distribution, movement etc.) in neurodegenerative diseases such as Parkinson's disease, Huntington's disease, amyotrophic lateral sclerosis, and Alzheimer's disease. Here, we provide a concise overview of the major findings in recent years highlighting the importance of healthy mitochondria for a healthy neuron.

\section{Introduction}

Mitochondria, aptly termed "powerhouses of the cell," are responsible for production of most of the cell's "energy currency," in the form of ATP. ATP is the end product of a series of pathways involving oxidation of substrates, mainly carbohydrates and fat, in cytosol (glycolysis) and mitochondria [pyruvate decarboxylation, tricarboxylic acid cycle (Krebs cycle), and oxidative phosphorylation (OXPHOS)/respiratory chain complex)]. The respiratory chain complex consists of four distinct multisubunit complexes (I-IV) and two electron carriers that generate a proton gradient across the mitochondrial inner membrane, which in turn drives ATP synthase (complex V) to generate ATP. Mitochondria are also the seat of many of the cell's housekeeping functions, including the

This work was supported by the National Institutes of Health National Institute on Aging [Grant P01AG14930] and the Huntington Disease Society of America Coalition for the Cure (M.F.B.)

Article, publication date, and citation information can be found at http://jpet.aspetjournals.org.

http://dx.doi.org/10.1124/jpet.112.192138. biosynthesis of amino acids and steroids, $\beta$-oxidation of fatty acids, maintenance of cytosolic calcium homeostasis, buffering of calcium fluctuations, and production and modulation of reactive oxygen species (ROS). Mitochondria also play a central role in apoptosis (Davis and Williams, 2012). Considering the intense energy demands and limited regenerative capacity of neurons, improper functioning of mitochondria can have devastating effects on neuronal survival. There is ample evidence of impaired mitochondrial function as a cause rather than consequence of neurodegeneration.

\section{Mitochondrial Dynamics}

Mitochondria are dynamic organelles that are transported on cytoskeletal proteins (mitochondrial trafficking). They fuse and divide (fusion is mediated by OPA1, Mfn1, and Mfn2, and fission is mediated by the proteins fission 1 and Drp1), fragment, swell, extend, and are recycled (mitophagy or vesicle formation) constantly and in a regulated fashion. Unbalanced fusion leads to mitochondrial elongation, and unbalanced fission leads to excessive mitochondrial fragmen-

\footnotetext{
ABBREVIATIONS: OXPHOS, oxidative phosphorylation; $A \beta, \beta$-amyloid peptide; AD, Alzheimer's disease; AICAR, 5-aminoimidazole-4-carboxamide ribonucleoside; ALS, amyotrophic lateral sclerosis; AMPK, AMP-activated protein kinase; APP, amyloid precursor protein; ARE, antioxidant response element; CDDO-MA, CDDOmethylamide; CoQ10, coenzyme Q10; COX, cytochrome c oxidase; DA, dopaminergic; Drp1, dynamin related-protein 1; HD, Huntington's disease; Hsp, heat shock protein; htt, huntingtin; mhtt, mutant htt; LRRK2, leucine-rich repeat kinase 2; Mfn, mitofusin; MMP, mitochondrial membrane potential; MPTP, 1-methyl-4-phenyl-1,2,3,6-tetrahydropyridine; mtDNA, mitochondrial DNA; NRF, nuclear respiratory factor; 3-NP, 3-nitropropionic acid; OMM, outer mitochondrial membrane; OPA1, optic atrophy 1; PD, Parkinson's disease; PGC-1 $\alpha$, peroxisome proliferator-activated receptor- $\gamma$ coactivator- $1 \alpha$; PINK1, phosphatase and tensin homolog-induced putative kinase 1 ; PPAR, peroxisome proliferator-activated receptor; PS, presenilin; ROS, reactive oxygen species; SIRT, silent mating type information regulation 2 homolog; SOD, superoxide dismutase; Tfam, mitochondrial transcription factor A; TP, triterpenoid.
} 
tation and small mitochondria, both of which impair the function of mitochondria. It has been shown that exchange of mitochondrial contents is important for mitochondrial function as well as organelle distribution in neurons. Mitochondrial fusion, in particular that mediated by $\mathrm{Mfn} 2$, is required for proper development and maintenance of the cerebellum (Chen et al., 2007). Mutations in the Mfn2 gene cause the neurodegenerative disease Charcot-Marie-Tooth type 2A, and mutations in OPA1 cause dominantly inherited optic atrophy. There is now increasing evidence of altered mitochondrial trafficking and fusion-fission dynamics in Alzheimer's disease (AD), Parkinson's disease (PD), Huntington's disease (HD), and amyotrophic lateral sclerosis (ALS).

\section{Mitochondrial Dysfunction, Altered Mitochondrial Dynamics, and Neurodegeneration}

AD. $\mathrm{AD}$ is defined by progressive impairments in memory and cognition and the presence of extracellular neuritic plaques and intracellular neurofibrillary tangles. $\beta$-Amyloid peptide $(A \beta)$ is the major component of the plaque, and the tangles are composed of hyperphosphorylated tau proteins. The molecular events leading to the development of sporadic late-onset $\mathrm{AD}$ have not been defined. Advanced age is the greatest risk factor for $\mathrm{AD}$, and glucose/energy metabolism is diminished in $\mathrm{AD}$. It has been proposed that in sporadic $\mathrm{AD}$ mitochondrial dysfunction is the primary event that causes $\mathrm{A} \beta$ deposition, synaptic degeneration, and formation of neurofibrillary tangles (Swerdlow et al., 2010). Energy deficiency is a fundamental characteristic feature of both $\mathrm{AD}$ brains and peripheral cells derived from patients with $\mathrm{AD}$ (Gibson et al., 1998; Manczak et al., 2004; reviewed in Beal, 2005). Activities of the three key tricarboxylic acid cycle enzyme complexes, pyruvate dehydrogenase, isocitrate dehydrogenase, and $\alpha$-ketoglutarate dehydrogenase, are impaired in postmortem $\mathrm{AD}$ brain and fibroblasts from patients with $\mathrm{AD}$ (Bubber et al., 2005). Reduced OXPHOS complex I, III, and IV activities have been reported in platelets and lymphocytes from patients with $\mathrm{AD}$ and in postmortem brain tissue (Kish et al., 1992; Bosetti et al., 2002) (summarized in Table 1). Several studies have reported impaired mitochondrial dynamics that involve the abnormal expression of Drp1 in postmortem brains from patients with $\mathrm{AD}, \mathrm{AD}$ mouse models, and APP cell lines (Cho et al., 2009; reviewed in Reddy et al., 2011). There is also impaired mitochondrial biogenesis (Sheng et al., 2012).

PD. PD is the second most common neurodegenerative disorder. Clinically, PD is characterized by the triad of resting tremor, bradykinesia, and rigidity. These symptoms are considered to be a direct consequence of neurodegeneration and loss of dopaminergic (DA) neurons. Pathologically, the hallmark feature of PD is loss of pigmented dopaminergic neurons in the substantia nigra and the presence of abnormal protein aggregates called Lewy bodies, which are cytoplasmic eosinophilic inclusions composed of the presynaptic protein $\alpha$-synuclein. Over the last several decades, evidence has accumulated that mitochondrial dysfunction is strongly associated with PD. A mild deficiency in mitochondrial elec-

TABLE 1

Known OXPHOS complex deficiencies in major neurodegenerative disorders

\begin{tabular}{|c|c|c|c|c|}
\hline OXPHOS Complex & Huntington's Disease & Alzheimer's Disease & Parkinson's Disease & Amyotrophic Lateral Sclerosis \\
\hline $\begin{array}{l}\text { Complex I (NADH } \\
\text { dehydrogenase or } \\
\text { NADH:ubiquinone } \\
\text { oxidoreductase) }\end{array}$ & $\begin{array}{l}\text { Unaltered in brain of } \\
\text { patients with HD, but } \\
\text { reduced in skeletal } \\
\text { muscle }\end{array}$ & $\begin{array}{l}\text { Reduced in mitochondria, } \\
\text { platelets, and lymphocytes } \\
\text { from patients with AD and } \\
\text { postmortem brain tissue }\end{array}$ & $\begin{array}{l}\text { Impaired complex I activity } \\
\text { is seen in substantia } \\
\text { nigra, platelets; and } \\
\text { skeletal muscle of } \\
\text { patients with; complex I } \\
\text { inhibitors are used to } \\
\text { model PD }\end{array}$ & $\begin{array}{l}\text { Increased in patients with } \\
\text { familial ALS with } \\
\text { SOD1 mutations, } \\
\text { reduced in skeletal } \\
\text { muscle samples from } \\
\text { patients with sporadic } \\
\text { ALS }\end{array}$ \\
\hline $\begin{array}{l}\text { Complex II (succinate } \\
\text { dehydrogenase) }\end{array}$ & $\begin{array}{l}\text { Reduced enzyme activity } \\
\text { in brain of patients } \\
\text { with advanced-stage } \\
\text { HD and in muscle of } \\
\text { transgenic mice; } \\
\text { complex II inhibitors } \\
\text { produce a HD } \\
\text { phenotype in mice and } \\
\text { primates }\end{array}$ & $\begin{array}{l}\text { Reduced in mitochondria from } \\
\text { patients with } \mathrm{AD}\end{array}$ & & $\begin{array}{l}\text { Complex II + III } \\
\text { activities are reduced in } \\
\text { spinal cords of patients } \\
\text { with ALS }\end{array}$ \\
\hline $\begin{array}{l}\text { Complex III } \\
\text { (CoQ-cytochrome } c \\
\text { reductase) }\end{array}$ & $\begin{array}{l}\text { Reduced enzyme activity } \\
\text { in patients with } \\
\text { advanced-stage HD }\end{array}$ & $\begin{array}{l}\text { Core } 1 \text { protein is significantly } \\
\text { reduced in temporal cortex } \\
\text { of patients with } \mathrm{AD} \text {; also } \\
\text { reduced in mitochondria, } \\
\text { platelets, and lymphocytes } \\
\text { from patients with } \mathrm{AD} \text { and } \\
\text { postmortem brain tissue }\end{array}$ & & $\begin{array}{l}\text { Complex I + III activities } \\
\text { reduced in spinal cords } \\
\text { of patients with ALS }\end{array}$ \\
\hline $\begin{array}{l}\text { Complex IV } \\
\text { (cytochrome } c \\
\text { oxidase) }\end{array}$ & $\begin{array}{l}\text { Reduced COX activity in } \\
\text { myoblasts and brain } \\
\text { samples from patients } \\
\text { with HD }\end{array}$ & $\begin{array}{l}\text { Decreased activity and mRNA } \\
\text { levels in brains, platelets } \\
\text { and lymphocytes from AD } \\
\text { patients }\end{array}$ & $\begin{array}{l}\text { Reduced complex IV } \\
\text { activity was reported in } \\
\text { platelet mitochondria } \\
\text { and skeletal muscle from } \\
\text { patients with PD }\end{array}$ & $\begin{array}{l}\text { Decreased COX activity in } \\
\text { individual motor } \\
\text { neurons, spinal cords } \\
\text { and skeletal, muscle of } \\
\text { patients with sporadic } \\
\text { ALS; decreased COX } \\
\text { subunits in G93A ALS } \\
\text { mice }\end{array}$ \\
\hline $\begin{array}{l}\text { Complex V (ATP } \\
\text { synthase) }\end{array}$ & $\begin{array}{l}\text { ATP production is } \\
\text { impaired in striatal } \\
\text { cells from mutant htt } \\
\text { mice }\end{array}$ & $\begin{array}{l}\text { Reduced in mitochondria from } \\
\text { patients with } A D\end{array}$ & $\begin{array}{l}\text { Reduced enzyme activity } \\
\text { for complex V in skin } \\
\text { fibroblast cultures from } \\
\text { patients with PD }\end{array}$ & $\begin{array}{l}\text { Levels of different } \\
\text { subunits }(\mathrm{D}, \alpha, \text { and } \beta) \\
\text { are decreased in G93A } \\
\text { ALS mice }\end{array}$ \\
\hline
\end{tabular}


tron transport chain NADH dehydrogenase (complex I) activity was first found in the substantia nigra of patients with $\mathrm{PD}$, followed by studies identifying a similar complex I deficit in platelets, lymphocytes, and, less consistently, in muscle tissue from patients with PD (reviewed in Beal, 2007). Consistent with this, inhibitors of OXPHOS complex I, such as rotenone and 1-methyl-4-phenyl-1,2,3,6-tetrahydropyridine (MPTP), in animal models, produce neuropathologic and behavioral symptoms similar to human PD. A number of proteins that are genetically linked to familial PD, phosphatase and tensin homolog-induced putative kinase 1 (PINK1), DJ-1, $\alpha$-synuclein, leucine-rich repeat kinase 2 , and parkin, are either mitochondrial proteins or are associated with mitochondria (Table 2). There is evidence to suggest that parkin and PINK1 have a direct role in the cell's mitochondrial quality-control pathways, identifying impaired mitochondria with reduced membrane potential and selectively eliminating them from the mitochondrial network by mitophagy. This implicates a failure of mitophagy as playing a role in the pathogenesis of PD (Narendra and Youle, 2011). Moreover, there is evidence for a direct involvement of PINK1 and parkin in abnormal mitochondrial dynamics in fly, rat, and mouse models of PD (Wang et al., 2011; reviewed in Reddy et al., 2011).

The "MitoPark" mice are an excellent example of the "mitochondrial hypothesis" of PD. In MitoPark mice mitochondrial function is selectively disrupted in DA neurons by elimination of the mitochondrial transcription factor A (Tfam) gene (Ekstrand et al., 2007). The Tfam gene is encoded in the nuclear genome, and the Tfam protein is subsequently imported into mitochondria, where it acts as a DNA binding protein, essential for both transcription and maintenance of mitochondrial DNA (mtDNA) in mammals. It stabilizes mtDNA, regulates mtDNA copy number in vivo, and is essential for mitochondrial biogenesis (Larsson et al., 1998). The MitoPark mice survive to adulthood and then slowly develop a Parkinsonian phenotype (Ekstrand et al., 2007; Galter et al., 2010). Furthermore, cellular changes similar to those seen in idiopathic PD are observed, such as intracellular inclusions in DA neurons, degeneration of DA pathways, and loss of striatal dopamine. Also similar to PD, the substantia nigra pars compacta DA neurons of MitoPark mice degenerate before those in the ventral tegmental area.

HD. HD is a dominantly inherited progressive neurodegenerative disease, caused by an abnormal CAG repeat expansion in the huntingtin (htt) gene. The disease is characterized by progressive motor impairment, personality changes, psychiatric illness, and gradual intellectual decline. Pathologically, there is a preferential and progressive loss of the medium spiny neurons in the striatum, as well as cortical atrophy, and degeneration of other brain regions later in the disease. There is extensive evidence for bioenergetic deficits and mitochondrial dysfunction in HD, such as a pronounced weight loss despite sustained caloric intake, NMR spectroscopy showing increased lactate in the cerebral cortex and basal ganglia, decreased activities of OXPHOS complexes II and III, reduced aconitase activity in the basal ganglia, abnormal mitochondrial membrane depolarization in patient lymphoblasts, abnormal ultrastructure of mitochondria in cortical biopsies obtained from patients with both juvenile and adult-onset HD, and pathologic-grade dependent reductions in numbers of mitochondria in HD postmortem brain tissue and in striatal cells from mutant htt (mhtt)-knock-in mice; both mitochondrial respiration and ATP production are significantly impaired (reviewed in Browne and Beal, 2004) (Table 1). We have shown that the phenotypic and neuropathologic features of HD can be modeled in rodents and primates with the mitochondrial toxin 3-nitropropionic acid (3-NP) (Beal et al., 1993). We and others have shown impaired brain creatine kinase activity and significant alterations in levels of highenergy phosphate intermediates in transgenic mouse models of HD (Zhang et al., 2011; Mochel et al., 2012). We also found a reduction in numbers and size of mitochondria, identified by a reduction in immunohistochemical markers for cytochrome $c$ oxidase 2 (COX2), superoxide dismutase (SOD) 2, and cytochrome $c$, that worsened with increasing disease severity (Kim et al., 2010). In addition, both the Tfam, a regulator of mtDNA transcription and replication, and peroxisome proliferator-activated receptor (PPAR)- $\gamma$ coactivator- $1 \alpha$ (PGC-1 $\alpha$ ), a key transcriptional regulator of energy metabolism and mitochondrial biogenesis, are significantly reduced as disease severity increases. Abnormalities in mitochondrial dynamics were observed: Drp1 was found to be significantly increased, and $\mathrm{Mfn} 1$ was significantly decreased (Kim et al., 2010). In addition, a direct interaction of mhtt with mitochondria or various protein complexes has been proposed to play an important role in disease pathogenesis, by regulating mitochondrial fission-fusion events and mitochondrial trafficking along axons and dendrites (reviewed in Bossy-Wetzel et al., 2008; Reddy et al., 2009; Johri et al., 2012) (Table 2).

ALS. ALS is a progressive neurodegenerative disease that targets motor neurons in the brain and spinal cord, resulting in muscle weakness, atrophy, and eventual death. Although there have been extensive research efforts investigating the pathogenesis of ALS, its etiology is still largely unknown. In approximately $20 \%$ of the familial ALS cases, the disease is associated with one or more mutations in the gene that encodes copper-zinc SOD1. Dominant mutations in two DNA/ RNA binding proteins, TDP-43 (TAR DNA-binding protein 43) and FUS/TLS (fused/translocated in liposarcoma), have also been reported and account for $\sim 5$ and $4 \%$ of ALS cases, respectively (Da Cruz and Cleveland, 2011). Mutations in the valosin-containing protein (also known as transitional endoplasmic reticulum ATPase) gene were recently reported to be the cause of 1 to $2 \%$ of familial ALS cases, and they have effects on the regulation of mitochondrial calcium (De Vos et al., 2012). The ultimate cause of neuronal death and the debilitating phenotypes in ALS are currently unknown; however, several studies have reported mitochondrial damage and dysfunction in patients with ALS and SOD1 mutant transgenic mice (reviewed in Beal, 2005). Furthermore, degenerating mitochondria in the perinuclear region have been reported in ALS transgenic mice with TDP-43 or FUS mutations. Mitochondrial abnormalities (e.g., swelling, deformed cristae, defects in respiratory chain activity, and a decrease in mtDNA copy number) are among the earliest signs of disease onset in the transgenic mouse models with SOD1 mutations. Disruption of axonal transport was shown in both patients with ALS and mutant SOD1 transgenic mice (reviewed in Magrané and Manfredi, 2009). A proportion of SOD1 mutant protein is misfolded onto the cytoplasmic surface of mitochondria, and the axonal mitochondria of motor neurons are the primary in vivo targets for misfolded SOD1 
TABLE 2

Proteins implicated in the pathogenesis of major neurodegenerative disorders and their association/interaction with mitochondria

\begin{tabular}{lll}
\hline Protein & Disease & Mitochondrial Association \\
\hline $\mathrm{htt}$ & $\mathrm{HD}$ & 1. Although largely cytosolic, htt is also present on outer mitochondrial membrane (OMM).
\end{tabular}

2. htt expression correlated with elevated lactate levels, decreased mitochondrial membrane potential (MMP), decreased respiratory function through complex II and defects in mitochondrial calcium uptake, reduced mitochondrial mobility and mitochondrial ultrastructural changes.

3. Rat cortical neurons treated with 3-nitropropionic acid have fragmentation and condensation of mitochondria that can be prevented by antioxidant treatment.

4. In HeLa cells overexpressing mhtt with a 74-glutamine repeat, there is fragmentation of mitochondria, reduced mitochondrial fusion, reduced ATP, and increased cell death. Expression of either dominantnegative profission protein Drp1, or profusion protein Mfn2, not only prevents this change in mitochondrial morphology but also restores ATP levels and attenuates cell death.

5. mhtt binds more tightly to Drp1 on mitochondria and triggers mitochondrial fragmentation.

6. mhtt increases Drp1 enzymatic activity, which results in defective anterograde mitochondrial movement and synaptic deficiencies.

1. APP accumulates in the protein import channels of mitochondria from human $\mathrm{AD}$ brains where it was found to be stably associated with translocases of the outer and inner mitochondrial membrane (TOM40 and TIM23).

2. Exposure of neuronal cells to conditioned medium from cells stably expressing mutant forms of APP leads to increased mitochondrial fission, loss of dendritic spines, and eventually cell death. This increase in mitochondrial fission was traced to elevated levels of S-nitrosylated Drp1. Increased levels of S-nitrosylated Drp1 were found in brain samples from patients with $\mathrm{AD}$ and $\mathrm{AD}$ mouse models.

3. APP overexpression in M17 neuroblastoma cells resulted in predominantly fragmented mitochondria, decreased levels of Drp1 and OPA1, and a defect in neuronal differentiation. Overexpression of Drp1 or OPA1 could partially rescue different aspects of these defects.

Presenilins, PS1 and PS2 AD 1. Presenilins form the $\gamma$-secretase complex that together with $\beta$-secretase cleaves APP to produce A $\beta$.

2. PS1 and PS2 are enriched in mitochondria-associated membranes, which is a specialized subcompartment of the endoplasmic reticulum involved in lipid metabolism and calcium homeostasis. PS1 presence was also reported in mitochondria.

3. Knockout of PS2 in contrast to PS1 results in reduced mitochondrial function in vivo.

4. PS2 increases endoplasmic reticulum-mitochondria tethering, which could result in a chronic, toxic mitochondrial $\mathrm{Ca}^{+2}$ overload.

$\mathrm{A} \beta$

1. Mitochondrial accumulation of $\mathrm{A} \beta$ has been shown in patients with $\mathrm{AD}$, $\mathrm{APP}$ transgenic mice, and cellular models of AD.

2. Mitochondria localized $\mathrm{A} \beta$ was shown to inhibit $\mathrm{A} \beta$ binding alcohol dehydrogenase, disrupt mitochondrial permeability transition pore functions, and impair the respiratory chain complex III and IV.

3. Intracellular accumulated $A \beta$ induces age-dependent changes, including depletion of presynaptic mitochondria, slowdown of bidirectional transports of axonal mitochondria, decreased synaptic vesicles, increased large vacuoles, and elevated synaptic fatigue.

4. Cells overproducing $A \beta$ showed impairment of mitochondrial function such as reduced mitochondrial respiration, strongly altered morphology, and reduced intracellular mobility of mitochondria. Antioxidants reduced $\mathrm{A} \beta$ production and rescued mitochondrial function.

5. A $\beta$ increases expression of mitochondrial fission genes and reduces the expression of fusion genes in vitro.

Tau

$\alpha-$ Synuclein

PD

Parkin

PD

PINK1

$\mathrm{PD}$
$\mathrm{AD} / \mathrm{PD}$ 1. Tau mediates the effects of $\mathrm{A} \beta$ on axonal transport and a reduction of tau protects against $\mathrm{A} \beta$-induced axonal transport abnormalities.

2. Hyperphosphorylated/overexpressed tau impairs axonal transport of mitochondria.

3. N-terminal truncated tau localizes to mitochondrial membranes and was found to be highly enriched in mitochondria from cryopreserved synaptosomes of human $\mathrm{AD}$ brains.

1. $\alpha$-Synuclein is present predominantly on OMM in mouse brain and on inner mitochondrial membrane in human brain.

2. Higher accumulation of $\alpha$-synuclein was reported in mitochondria from striatum and substantia nigra of PD patients compared with normal subjects.

3. Accumulation of $\alpha$-synuclein in the mitochondria of human dopaminergic neurons reduced mitochondrial complex I activity and increased production of ROS.

4. N-terminal 32 amino acids of $\alpha$-synuclein were shown to function as a targeting sequence for the import of $\alpha$-synuclein into mitochondria in an energy- and import channel-dependent manner.

5. Mitochondrial association of $\alpha$-synuclein in cells was linked to oxidation of mitochondrial proteins and increased levels of calcium and nitric oxide.

6. Mitochondrial abnormalities were observed in transgenic mouse models overexpressing wild-type or mutant $\alpha$-synuclein: selective oxidation of mitochondria-associated metabolic proteins; degenerating mitochondria containing $\alpha$-synuclein; reduced complex IV activity; mitochondrial DNA damage; and increased mitochondrial pathology after treatment with MPTP.

7. Studies in $\alpha$-synuclein knockout mice suggest that $\alpha$-synuclein controls synaptic vesicle dynamics and may regulate mitochondrial membrane lipid composition and complex I activity.

1. Parkin is a largely cytosolic E3 ubiquitin ligase, which, along with PINK1, is involved in mitochondrial quality control pathways, i.e. mitophagy.

2. Although primarily cytosolic, Parkin is recruited to mitochondria under conditions of bioenergetic stress/ loss of mitochondrial membrane potential such as in presence of chemical uncouplers and OXPHOS inhibitors; by relatively long exposure to oxidative stress (after treatment with paraquat); chronic loss of mitochondrial fusion, or loss of mtDNA integrity.

3. Loss of Parkin in Drosophila melanogaster not only causes degeneration of flight muscles and dopaminergic neurons, but their mitochondria become dysmorphic and dysfunctional with less efficient OXPHOS and increased ROS production.

4. Parkin ubiquitinates OMM proteins, voltage-dependent anion channel 1 in mammals and Marf (an ortholog of mammalian mitofusins) in D. melanogaster. Ubiquitination (therefore elimination/inhibition) of Marf by Parkin promotes mitochondrial fission.

1. PINK1 gene encodes a mitochondrially localized serine/threonine kinase. PINK1 is normally kept at low levels on the OMM of healthy mitochondria. However, it is also imported into mitochondria and rapidly and selectively accumulates on the outer membrane of mitochondria that have lost membrane potential. 
TABLE 2-(Continued)

Protein Disease

Mitochondrial Association

2. Mutations in the PINK1 and Parkin genes result in enlarged or swollen mitochondria.

3. D. melanogaster null for Pink1 have the same unusual phenotype as Parkin knockout flies.

4. PINK1 was associated genetically with proteins involved in mitochondrial morphogenesis such as HtrA2, Drp1, and Opa1/Mfn2.

5. PINK1 acts upstream of Parkin, and expression of PINK1 is necessary for the recruitment of Parkin to depolarized mitochondria. Parkin recruitment tags the impaired mitochondria for degradation (mitophagy).

6. Mice null for Pink1 or Parkin exhibit synaptic dysfunction in neurons projecting to the striatum, and this synaptic dysfunction correlates with progressive loss of mitochondrial function and increased oxidative stress in the striatum with age.

7. Loss-of-function mutations in PINK1 or Parkin have also been associated with mitochondrial dysfunction in cells from patients with familial forms of parkinsonism

8. PINK1 phosphorylates Miro (which links mitochondria to microtubules via kinesin and Milton, for transport), resulting in Parkin-dependent proteasomal degradation of Miro. This prevents mitochondrial movement and probably quarantines damaged mitochondria before clearance by mitophagy.

9. Phosphorylation of Drp1 and the mitochondrial intermembrane proteins, TRAP-1 and HtrA2/Omi, also depends on PINK1. HtrA2 phosphorylation increases its proteolytic activity and may serve to proteolytically degrade misfolded mitochondrial proteins to maintain mitochondrial integrity. HtrA2 phosphorylation is decreased in brains of patients with PD carrying mutations in PINK1.

1. DJ-1 protein is located mostly in the cytosol, and only a fraction is present in the nucleus and mitochondria, where it preferentially partitions to the matrix and intermembrane space of mitochondria and it impairs degradation.

2. Upon oxidative stress, DJ-1 protein rapidly translocates to the mitochondria and, to a lesser extent, to the nucleus, acting as a neuroprotective intracellular redox sensor.

3. DJ-1 and its mutants were found to be strongly associated with Hsp70, the cochaperone CHIP, and a mitochondria-resident Hsp70 complex in patients with PD. In vitro, association of wild-type DJ-1 with mitochondrial Hsp70 was further increased under oxidative stress, indicating that the translocation of DJ1 to mitochondria may occur by binding to mitochondrial chaperones.

4. DJ-1 protects dopaminergic neurons from oxidative stress by stabilizing Nrf2 and through up-regulation of glutathione synthesis and from the toxic consequences of A53T $\alpha$-synuclein through increased expression of Hsp70.

5. DJ-1 knockout in fly and mice produced decreased mtDNA levels, respiratory control ratio, and ATP levels. DJ-1-deficient mice are more sensitive to MPTP-induced loss of dopamine neurons.

6. Loss of DJ-1 in flies and mice was associated with increased sensitivity of mitochondria to complex I inhibitors and oxidative stress.

7. In vitro, reduction of DJ-1 was associated with lowered MMP, an increase in mitochondria fragmentation, autophagy and oxidative stress, and reduced mitochondrial fusion. DJ-1 was also found to directly bind to the mitochondrial complex I subunits; and loss of function of DJ-1 led to a decrease of mitochondrial complex I activity, but not complex III; whereas overexpression of DJ-1 conferred protection against the complex I inhibitor MPTP.

8. DJ-1 inhibits the aggregation and toxicity of $\alpha$-synuclein by increasing Nrf2, a direct interaction is not known; DJ-1 binds to PINK1 and increases PINK1 levels under conditions of PINK1 overexpression; DJ-1 and Parkin interact under conditions of oxidative stress.

9. DJ-1 activates transcription of the Mn-SOD gene, which encodes an essential mitochondrial antioxidant enzyme.

1. LRRK2 immunoreactivity was shown to partially overlap with mitochondrial and lysosomal markers in the mammalian brain, and ultrastructural analysis revealed that LRRK2 is associated with intracellular membranes, including lysosomes, transport vesicles, and mitochondria.

2. LRRK2 can bind to the OMM in mammalian brain. Approximately $10 \%$ of wild-type and mutant LRRK2 were present in the mitochondrial fraction in cells overexpressing the proteins.

3. Patients with a G2019S mutation had a decrease in MMP and ATP.

4. Overexpression of G2019S mutant LRRK2 in differentiated human neuroblastoma cells caused neurite retraction and shortening, which correlated with increased autophagy.

5. LRRK2 mutations increase the kinase activity of LRRK2, which results in increased neurotoxicity.

6. Overexpression of either wild-type or mutant (R1441C or G2019S) LRRK2 caused mitochondrial fragmentation, reduced mitochondrial fusion, and increased Drp1 recruitment to mitochondria by direct interaction with LRRK2 in vitro.

ALS 1. Wild-type SOD1 is predominantly cytosolic; however, a small fraction resides in mitochondria.

2. SOD1 and its copper chaperone, CCS, enter mitochondria through the Erv1/Mia40 oxidative folding mechanism of import, which involves a formation of mixed disulfide bonds between CCS and Mia40, and is sensitive to oxygen concentrations.

3. Wild-type SOD1 helps in the prevention of the oxidation of mitochondrial proteins and thus in the preservation of mitochondrial homeostasis. Mice lacking SOD1 show a distal motor neuropathy accompanied by decreased mitochondrial density and increased oxidative stress in mitochondria, which is rescued by SOD1 targeted to the mitochondrial intermembrane space.

4. A proportion of SOD1 mutant protein is misfolded onto the cytoplasmic surface of mitochondria, and the axonal mitochondria of motor neurons are the primary in vivo targets for misfolded SOD1.

5. A small fraction of the enzyme resides in various mitochondrial subcompartments, mutant SOD1 to a greater extent than wild type.

6. Mutant SOD1 alters axonal mitochondrial morphology and distribution.

7. Somal mitochondria are altered by mutant SOD1, with loss of the characteristic cylindrical, networked morphology and its replacement by a less elongated, more spherical shape.

8. Mutant SOD1 motor neurons have impaired mitochondrial fusion in both the axons and cell bodies; there is selective impairment of retrograde axonal transport, smaller mitochondrial size, decreased mitochondrial density, and defective MMP.

9. Expression of mutant SOD1 elicits a clear deficit in the electron transport chain, mishandling of mitochondrial calcium, increased production of ROS, and activation of the apoptotic pathway.

10. Overexpression of mutant SOD1 induces the activation autophagy, as measured by the activation of LC3 (microtubule-associated protein 1 light chain 3 ) and increases the association of PINK1 with mitochondria. 
(Vande Velde et al., 2011). Mutant SOD1 alters axonal mitochondrial morphology and distribution, with dismutase active SOD1 causing mitochondrial clustering at the proximal side of Schmidt-Lanterman incisures within motor axons, and dismutase inactive SOD1 producing aberrantly elongated axonal mitochondria beginning presymptomatically and increasing in severity as the disease progresses. Somal mitochondria are altered by mutant SOD1, with loss of the characteristic cylindrical, networked morphology and its replacement by a less elongated, more spherical shape (Vande Velde et al., 2011). Recently, Magrané et al. (2012) showed that mutant SOD1 motor neurons have impaired mitochondrial fusion in both axons and cell bodies. There is selective impairment of retrograde axonal transport, smaller mitochondrial size, decreased mitochondrial density, and defective mitochondrial membrane potential. Furthermore, mislocalization of mitochondria at synapses among motor neurons in vitro correlates with abnormal synaptic number, structure, and function (Magrané et al., 2012). Expressing mutant SOD1 confined to mitochondria is sufficient to produce loss of motor neurons and an ALS phenotype (Igoudjil et al., 2011).

\section{Mitochondrial DNA Mutations and Neurodegeneration}

Mitochondria have their own DNA (mtDNA) that encodes 13 of the 92 polypeptides of the OXPHOS system; the remaining structural polypeptides and assembly factors are encoded by nuclear DNA. Mutations in either mtDNA or nuclear DNA, resulting in OXPHOS dysfunction, are particularly known to affect tissues with high energy demands such as the central nervous system, skeletal muscle, and heart. Mitochondria are thought to contribute to aging through the accumulation of mtDNA mutations and net production of ROS. Mitochondrial DNA mutations, mitochondrial abnormalities, and mitochondrial respiratory chain-deficient cells are also present in age-related neurodegenerative diseases such as PD and AD (De Coo et al., 1999; Coskun et al., 2004; Smigrodzki et al., 2004; Parker and Parks, 2005; Bender et al., 2006, 2008; Reeve et al., 2008). The types of mtDNA deletions in the substantia nigra neurons from patients with $\mathrm{PD}$ and age-matched controls were found to be similar to those that occur in patients with Kearns-Sayre, Twinkle, or multiple-deletion disorder (Reeve et al., 2008).

\section{Peroxisome Proliferator-Activated Receptor- $\gamma$ Coactivator-1 $\alpha$ in Mitochondrial Dysfunction and Neurodegeneration}

Peroxisome proliferator-activated receptor (PPAR)- $\gamma$ coactivator (PGC)- $1 \alpha$ is a transcriptional coactivator that interacts with a broad range of transcription factors involved in a wide variety of biological processes and/or responses including mitochondrial biogenesis, OXPHOS, antioxidant defense, adaptive thermogenesis, glucose/fatty acid metabolism, fiber type switching in skeletal muscle, and heart development (Puigserver and Spiegelman, 2003; Liang and Ward, 2006; St-Pierre et al., 2006). PGC-1 $\alpha$ does not bind to DNA directly, but forms heteromeric complexes with transcription factors, including nuclear respiratory factors, NRF-1 and NRF-2, and the nuclear receptors, PPAR $\alpha$, PPAR $\delta$, PPAR $\gamma$, and estrogenrelated receptor $\alpha$ (Lin et al., 2005). These transcription factors, in turn, regulate the expression of many nuclearencoded mitochondrial genes, such as cytochrome $c$, complexes I to V, and Tfam (Kelly and Scarpulla, 2004; Handschin and Spiegelman, 2006). In recent years, impaired PGC-1 $\alpha$ expression and/or function has emerged as a common underlying cause of mitochondrial dysfunction in neurodegenerative diseases such as $\mathrm{HD}, \mathrm{PD}$, and $\mathrm{AD}$.

There is substantial evidence for the impairment of PGC- $1 \alpha$ levels and activity in HD (Cui et al., 2006; Weydt et al., 2006; Chaturvedi et al., 2009, 2010; Johri et al., 2011b). The involvement of PGC- $1 \alpha$ in HD was first indicated by the findings that PGC- $1 \alpha$ knockout mice exhibited mitochondrial dysfunction, defective bioenergetics, a hyperkinetic movement disorder, and striatal degeneration, which are features also observed in HD (Lin et al., 2004; Leone et al., 2005). Selective ablation of PGC- $1 \alpha$ leads to increased striatal neuron degeneration and increased susceptibility to the mitochondrial toxin 3-NP in HD transgenic mice (Cui et al., 2006). Furthermore, impaired PGC-1 $\alpha$ function and levels occur in striatal cell lines, transgenic mouse models of $\mathrm{HD}$, and postmortem brain tissue from patients with HD (Cui et al., 2006; Weydt et al., 2006). We showed a pathologic grade-dependent significant reduction in numbers of mitochondria in striatal spiny neurons, which correlated with reductions in PGC- $1 \alpha$ and Tfam (Kim et al., 2010). Sequence variation in the PGC- $1 \alpha$ gene modifies the age of onset of HD (TaherzadehFard et al., 2009; Weydt et al., 2009). Recent studies showed that expression of mhtt in primary oligodendrocytes results in decreased expression of PGC- $1 \alpha$, and decreased expression of myelin basic protein and deficient myelination were found in the R6/2 mouse model of HD (Xiang et al., 2011). A decrease in myelin basic protein and deficient postnatal myelination also occurs in the striatum of PGC- $1 \alpha$ knockout mice (Xiang et al., 2011).

A meta-analysis of 17 independent genomewide gene expression microarray studies revealed the strongest association between PD and nuclear genes encoding for OXPHOS subunits in mitochondria and enzymes involved in glucose metabolism, all of which are regulated by PGC-1 $\alpha$ (Zheng et al., 2010). These genes showed decreased expression in (laser microdissected) substantia nigra dopaminergic neurons even in the earliest stages of PD. Activation of PGC- $1 \alpha$ results in increased expression of OXPHOS subunits and blocks the dopaminergic neuron loss induced by mutant $\alpha$-synuclein, or the pesticide rotenone, in cultured dopaminergic neurons from embryonic rat midbrain and human catecholaminergic SH-SY5Y cells (Zheng et al., 2010). Transgenic mice overexpressing PGC-1 $\alpha$ in dopaminergic neurons are resistant against cell degeneration induced by the neurotoxin MPTP (Mudò et al., 2012). Earlier, it was noted that genetic ablation of the PGC- $1 \alpha$ gene markedly enhances MPTP-induced loss of tyrosine hydroxylase-positive neurons in the substantia nigra (St-Pierre et al., 2006). Recently, a parkin-interacting substrate was identified that accumulates in models of parkin inactivation and human PD brain, and it was shown to repress the expression of PGC- $1 \alpha$ and its target gene, NRF-1, by binding to insulin response sequences in the PGC- $1 \alpha$ promoter (Shin et al., 2011). Clark et al. (2011) provided limited evidence of an association of certain PGC- $1 \alpha$ singlenucleotide polymorphisms with the risk or age of onset of PD.

Using genomewide complementary DNA microarray analysis, Qin et al. (2009) showed that PGC- $1 \alpha$ expression is 
decreased in the brain of patients with $\mathrm{AD}$ as a function of dementia severity. PGC- $1 \alpha$ protein content was negatively associated with both $\mathrm{AD}$-type neuritic plaque pathology and $\beta$-amyloid contents. Qin et al. also showed that adenoviralmediated exogenous PGC- $1 \alpha$ expression in Tg2576 neurons attenuated hyperglycemic-mediated $\beta$-amyloidogenesis.

Recently, Liang et al. (2011) showed an age-dependent decrease in PGC-1 $\alpha$ in SOD1-G93A mice. Moreover, they showed that overexpression of PGC- $1 \alpha$ slowed the progression of ALS, moderately extended lifespan, and improved motor (rotarod) performance. These improvements were associated with a significant decrease in motor neuron cell death and less neuromuscular junction damage in the G93A mice that overexpressed PGC-1 $\alpha$ (Liang et al., 2011). In the same year, the Pasinetti laboratory also showed that PGC-1 $\alpha$ overexpression significantly improved motor function and survival of SOD1-G93A mice (Zhao et al., 2011). The behavioral improvements were accompanied by reduced blood glucose levels and protection against motor neuron loss, restoration of mitochondrial electron transport chain activities, and inhibition of stress signaling in the spinal cord (Zhao et al., 2011).

\section{Transcriptional Approaches to Improve Mitochondrial Function}

PGC-1 $\alpha$ and PPARs. PGC- $1 \alpha$ is now increasingly being recognized as an important therapeutic target for neurodegenerative disorders. As discussed above, PGC-1 $\alpha$ expression and/or function is impaired in all major neurodegenerative diseases; therefore, pharmacologic/transcriptional activation of the PGC- $1 \alpha$ pathway is expected to have neuroprotective effects. Indeed, overexpression of PGC- $1 \alpha$ was shown to reduce $\mathrm{A} \beta$ plaque in an in vitro model of $\mathrm{AD}$, produce neuroprotective effects in a transgenic mouse model of ALS, and enhance the mitochondrial membrane potential and reduce mitochondrial toxicity in in vitro models of HD (Weydt et al., 2006; Qin et al., 2009; Liang et al., 2011; Zhao et al., 2011). Lentiviral delivery of PGC- $1 \alpha$ to the striatum of R6/2 HD mice prevented striatal atrophy at the site of PGC- $1 \alpha$ injections (Cui et al., 2006). Recently, Da Cruz et al. (2012) showed that increasing PGC-1 $\alpha$ activity in muscle in a transgenic mouse model of ALS caused by a mutation in SOD1 is able to sustain muscle function throughout the disease course, although survival was not extended. Another potential approach to activating the PGC- $1 \alpha$ pathway, and thereby improving mitochondrial function, is via activation of PPARs. The PPARs are a subfamily of nuclear receptors that are ligand-modulated transcription factors that regulate geneexpression programs of metabolic pathways. PPAR agonists increase oxidative phosphorylation capacity in mouse and human cells and enhance mitochondrial biogenesis. Administration of a PPAR $\gamma$ agonist, thiazolidinedione, was shown to produce beneficial effects on weight loss, mhtt aggregates, and global ubiquitination profiles in R6/2 mice (Chiang et al., 2010). Earlier, it was shown in STHdhQ111 cells that PPARy activation by rosiglitazone prevents mitochondrial dysfunction and oxidative stress that occurs when mutant striatal cells are challenged with pathological increases in calcium (Quintanilla et al., 2008). We recently showed that bezafibrate, which is a pan-PPAR agonist, improved the expression of PGC- $1 \alpha$ and downstream target genes, improved behav- ioral deficits, survival, and striatal atrophy, and reduced oxidative damage in the R6/2 transgenic mouse model of $\mathrm{HD}$ (Johri et al., 2012). Both pioglitazone and rosiglitazone, which are PPAR- $\gamma$ agonists, were shown to exert beneficial effects in in vitro and in vivo models of $\mathrm{PD}$ and $\mathrm{AD}$ (reviewed in Chaturvedi and Beal, 2008; Mandrekar-Colucci and Landreth, 2011).

PGC-1 $\alpha$, SIRT1, and AMP-Activated Protein Kinase. Sirtuins (silent information regulators) are members of the $\mathrm{NAD}^{+}$-dependent histone deacetylase family of proteins in yeast, and its homologs in mice and humans participate in a variety of cellular processes, including mitochondrial functions, cellular metabolism, energy metabolism, gluconeogenesis, cell survival, and aging. Although the role of sirtuins in promoting lifespan extension in lower organisms has been contested recently, there is strong evidence to suggest that sirtuins are an integrative link between metabolic control and transcriptional regulation, and the role of SIRT1 in activating the master regulator PGC- $1 \alpha$ remains uncontested. Increased intracellular $\mathrm{NAD}^{+}$concentrations activate SIRT1 in brain after caloric restriction, resulting in a reduction in amyloid pathology in a mouse model of AD; increased SIRT1 protects against hippocampal degeneration in a mouse model of $\mathrm{AD}$, and direct injection of SIRT1 lentivirus in the hippocampus of $\mathrm{AD}$ transgenic mice produces significant neuroprotection (reviewed in Chaturvedi and Beal, 2008). A SIRT1 activator, resveratrol, increases the activity of PGC- $1 \alpha$ and improves mitochondrial activity as a consequence of SIRT1mediated deacetylation of PGC- $1 \alpha$, which increases its effects on liver, fat, and muscle metabolism. SIRT1 activation by resveratrol increases the survival of motor neurons in transgenic ALS mice and reduces learning impairments and neurodegeneration in $\mathrm{AD}$ mouse models, by decreasing the acetylation of the SIRT1 substrates PGC-1 $\alpha$ and p53 (Kim et al., 2007). Resveratrol also protects against 3-NP-induced motor and behavioral deficits. We showed that resveratrol treatment of the N171-82Q HD transgenic mice produced increased PGC- $1 \alpha$ and reduced the apparent vacuolization in brown adipose tissue and reduced glucose levels, but there were no beneficial effects in the striatum, probably because of poor brain penetration (Ho et al., 2010). Overexpression of SIRT1 improves motor function, reduces brain atrophy, and attenuates mhtt-mediated metabolic abnormalities in three different transgenic mouse models of HD (Jeong et al., 2012; Jiang et al., 2012). Recently, it was shown that SIRT1 protects against $\alpha$-synuclein aggregation by activating molecular chaperones, heat shock factor 1 and Hsp70, in the brains of mice with the A53T $\alpha$-synuclein mutation (Donmez et al., 2012). Another sirtuin, which is of particular interest as a target for therapeutic intervention, is SIRT3. It is one of the three sirtuins that are located in mitochondria, where it interacts with complex I of the respiratory chain and deacetylates several proteins in complex I. It also increases fatty acid oxidation, SOD2 activity, and levels of glutathione and inhibits activation of the mitochondrial permeability transition.

AMP-activated protein kinase (AMPK) is a Ser/Thr kinase that is activated as a consequence of increased AMP levels, reflecting low ATP availability and low energy reserve. AMPK activation results in a cascade of phosphorylationdependent adaptive modifications of several factors, including PGC- $1 \alpha$, to switch on the catabolic pathways (such as 
fatty acid oxidation and mitochondrial respiratory chain activity) to produce ATP, while simultaneously shutting down energy-consuming anabolic processes. 5-Aminoimidazole-4carboxamide ribonucleoside (AICAR) is a compound that has been used to activate PGC- $1 \alpha$ through AMPK. It does so by generating inosine monophosphate, which acts as an AMPK agonist by mimicking AMP. AICAR was shown to inhibit tau phosphorylation in an in vitro model of $\mathrm{AD}$; however, AMPK activation by AICAR was shown to produce adverse effects in R6/2 HD mice in that it enhanced brain atrophy, neuronal loss, and aggregate formation in the striatum. Recently, it was shown that AMPK activity is increased in spinal cord cultures expressing mutant SOD1, as well as in spinal cord lysates from mutant SOD1 mice (Lim et al., 2012). Reducing AMPK activity either pharmacologically or genetically prevented mutant SOD1-induced motor neuron death in vitro (Lim et al., 2012). Metformin is another AMPK activator that was shown to be effective in male HD transgenic mice in that it prolonged survival and decreased hind limb clasping ( $\mathrm{Ma}$ et al., 2007).

Although the effects of resveratrol and SIRT1 on PGC-1 $\alpha$ are well established, lately there has been a great deal of controversy about the mechanism by which this regulation is achieved. The ability of resveratrol to elicit cellular changes in a SIRT1-independent manner, combined with the observations that AMPK-deficient mice exhibit a blunted response to resveratrol treatment, pointed toward AMPK as a critical mediator of resveratrol action (Um et al., 2010). Studies by Park et al. (2012) suggested that resveratrol does not target SIRT1 directly but instead stimulates the AMPK pathway by inhibiting cAMP-degrading phosphodiesterases (mainly phosphodiesterase 4), resulting in increased cAMP levels, which in turn increases cellular calcium levels, thereby stimulating the phosphorylation of AMPK (Park et al., 2012). It was proposed that AMPK then activates SIRT1 indirectly by elevating intracellular levels of its cosubstrate, $\mathrm{NAD}^{+}$(Fulco et al., 2008; Canto et al., 2009). Recently, this issue was addressed in an elegant manner in a study by Sinclair's group, which used a conditional SIRT1 knockout mouse to show that with moderate doses of resveratrol in vitro or in vivo the increases in phosphorylated $\mathrm{AMPK}, \mathrm{NAD}^{+}$, liver kinase B1 acetylation, and mitochondrial function entirely depended on SIRT1 (Price et al., 2012). Using this adultinducible SIRT1 knockout mouse strain, Price et al. showed that the beneficial effects of resveratrol treatment on muscle mitochondrial function depend on SIRT1 in vivo. They also showed that overexpression of SIRT1 in a transgenic mouse strain mimicked the effects of resveratrol treatment in skeletal muscle. These studies support a model in which lower doses of resveratrol stimulate SIRT1 upstream of AMPK via deacetylation of liver kinase B1, one of the activating protein kinases of AMPK (Price et al., 2012). At present, the entire resveratrol/sirtuin field seems to be changing at daunting speed, and much remains to be proven/disproven about the elusive mechanisms of action of resveratrol and sirtuins and their potential role in neurodegeneration and life extension. However, the beneficial effects of resveratrol and SIRT1 that were observed in several mouse models of neurodegenerative diseases cannot be overlooked, and the quest for small-molecule activators of sirtuins with potential neuroprotective effects should continue.
Nrf2/Antioxidant Response Element Pathway. ROS damage to mitochondria is well known in all of the major neurodegenerative disorders; therefore, therapies targeting the Nrf2/antioxidant response element (ARE) pathway are of particular interest. Synthetic triterpenoids (TPs) are analogs of oleonolic acid and powerful inhibitors of oxidative stress and cellular inflammatory processes. Synthetic TP compounds are potent inducers of the ARE/Nrf2/Keap1 signaling pathway. After activation by TP, Nrf2 dissociates from Keap1, translocates to the nucleus, and binds to the ARE promoter sequences, leading to coordinated induction of a battery of cytoprotective genes, including antioxidants and anti-inflammatory genes. Neuronal cultures derived from Nrf2 knockout mice show increased susceptibility to oxidative damage, as well as damage produced by mitochondrial electron transport gene complex inhibitors such as $\mathrm{MPP}^{+}$ and rotenone. Nrf2-deficient mice show increased susceptibility to the mitochondrial toxins MPTP and 3-NP. Recently, we tested neuroprotective effects of the synthetic triterpenoid CDDOmethylamide (CDDO-MA), which is a potent activator of the Nrf2/ARE signaling pathway (Yang et al., 2009a). CDDO-MA produced marked protection in the 3 -NP rat model and both the acute and chronic MPTP mouse models. CDDO-MA exerted significant protection against tertbutylhydroperoxide-induced ROS in vitro. It increased the expression of genes involved in mitochondrial biogenesis, as well as those involved in glutathione synthesis and in the expression of antioxidant enzymes (Yang et al., 2009a). Triterpenoids also protect in transgenic mouse models of ALS, HD, and AD.

Several bioenergetic agents have efficacy in improving mitochondrial function including creatine, coenzyme Q10 (CoQ10), nicotinamide, riboflavin, and lipoic acid (reviewed in Beal, 2009). CoQ10 is an essential biologic factor of electron transport chain where it accepts electrons from complexes I and II. It also serves as an important antioxidant in mitochondrial lipid membranes. We showed that oral administration of CoQ10 protects against lesions produced by amino-oxyacetic acid and the mitochondrial toxins malonate and 3-NP. We also found modest neuroprotective effects of COQ10 in a transgenic mouse model of ALS and more marked neuroprotective effects in transgenic mouse models of HD. We recently found that CoQ10 treatment decreases brain oxidative stress, A $\beta 42$ levels, and $\beta$-amyloid plaque area and number, and improves cognition in a transgenic mouse model of $\mathrm{AD}$ (Dumont et al., 2011). High doses of CoQ10 significantly extend survival and improve motor performance, grip strength, and brain atrophy in R6/2 HD mice in a dose-dependent manner. Furthermore, we found that the combination of creatine and CoQ10 exerts additive neuroprotective effects in the MPTP model of $\mathrm{PD}$, the 3-NP model of HD, and a transgenic mouse model of HD (Yang et al., 2009b). These compounds, therefore, show neuroprotective effects, which may be a useful target for treating neurodegenerative diseases.

A new concept emerging in the field of neurodegenerative diseases, and which opens up new avenues for understanding disease progression and developing novel therapeutics, is that of the prion-like spread of misfolded proteins. The prion concept was developed by Prusiner (1998) and involves proteinaceous particles, the prions, which are the infectious agents in Jacob-Creutzfeld and other neurological disorders. This concept may also be applicable to neurodegenerative diseases with genetic experiments providing convincing evi- 


\section{5-aminoimidazole-4-carboxamide} ribonucleoside (AICAR)<smiles>CCc1ccc(CCOc2ccc(C[C@H]3SC(=O)NC3=O)cc2)nc1</smiles><smiles></smiles><smiles>Oc1ccc(C=Cc2cc(O)cc(O)c2)cc1</smiles><smiles>NC(=O)c1ncn(C2OC(CO)C(O)C2O)c1N</smiles>

Bezafibrate<smiles>CC(C)(Oc1ccc(CCNC(=O)c2ccc(Cl)cc2)cc1)C(=O)O</smiles>

Fig. 1. Structures of the compounds that produce beneficial effects in mice against mitochondrial dysfunction.<smiles>COC1=C(OC)C(=O)C(CC=C(C)CCC=C(C)CCC=C(C)CCC=C(C)CCC=C(C)CCC=C(C)CCC=C(C)CCC=C(C)CCC=C(C)CCC=C(C)C)=C(C)C1=O</smiles>

CDDO-Ethylamide<smiles>CCNC(=O)C12CCC(C)(C)CC13CC(C)(C)C1(C)CCC4(C)C(=CC(=O)C42C)C3(C)C=C(C#N)C(=O)C1(C)C</smiles>

CDDO-Trifluoroethylamide<smiles>CC1(C)CCC2(C(=O)NCC(F)F)CCC3(C)C4(C)CCC5(C)C(C)(C)C(=O)C(C#N)=CC5(C)C4=CC(=O)C3(C)C2C1</smiles>

dence that mutant $\mathrm{A} \beta, \alpha$-synuclein, and tau can be transferred between neighboring neurons, and then induce pathological changes in these neurons (Harris et al., 2010; Luk et al., 2012; de Calignon et al., 2012).

\section{Conclusion and Future Perspectives}

As discussed above, there is strong evidence implicating the role of mitochondrial dysfunction in the pathogenesis of neurodegenerative diseases. In a number of instances, there is direct involvement of the genetic defect with mitochondria such as in Friedreich's ataxia. In a number of neurodegenerative diseases, the genetic evidence is more indirect. This is the case in $\mathrm{AD}$ and $\mathrm{HD}$. In $\mathrm{AD}$, the mitochondrial dysfunction may be a consequence of the accumulation of $\mathrm{A} \beta$ within mitochondria. Likewise, in PD $\alpha$-synuclein has been demonstrated to associate with mitochondria, and recent studies have shown that LRRK2, which is localized on the outer surface of mitochondria, may increase mitochondrial fission (Niu et al., 2012). The autosomal recessive genes involved in PD all are linked to mitochondrial dysfunction. For instance, both parkin and PINK1 play a role in mitophagy, and DJ-1 modulates oxidative damage within mitochondria. In $\mathrm{HD}$, the mitochondrial impairment may be caused by an impairment of the activity of PGC- $1 \alpha$, although there is other evidence that mutant htt can directly associate with mitochondria and may increase mitochondrial fission (Costa et al., 2010; Johri et al., 2011a; Shirendeb et al., 2011; Song et al., 2011). There is recent evidence showing an impairment of PGC- $1 \alpha$ in PD based on findings in microarray studies and transgenic mouse models in which a parkin deficiency leads to impaired PGC- $1 \alpha$ transcription, which is caused by an accumulation of parkin-interacting substrate (Shin et al., 2011).

The field of mitochondrial dynamics, which is involved in the trafficking and turnover of mitochondria, is another area 
in which there is increasing evidence for a critical role in neurodegenerative diseases. Mutations in the mitochondrial fusion proteins, mitofusin 2 and OPA1, are responsible for Charcot-Marie tooth disease and autosomal dominant optic atrophy, respectively. Mutant htt binds to DRP1 and increases its GTPase activity, and similar effects have been reported in $\mathrm{AD}$ (Manczak et al., 2011). There is evidence that mutant SOD1, a cause of autosomal dominant ALS, forms aggregates, which then bind to the outer mitochondrial membrane impairing the activity of the voltage-dependent anion channel, Bcl-2, as well as impairing protein uptake (Israelson et al., 2010).

The field of mitochondrial-targeted therapeutics is one that is growing and is of great importance. The development of transgenic mouse models of neurodegenerative diseases has been valuable in providing ways of testing and developing new therapies. Creatine is involved in buffering energy metabolism, produces neuroprotective effects in transgenic mouse models of HD and ALS, and is protective in the MPTP model of PD (Beal, 2011). It is presently being tested in phase III clinical trials in both PD and HD. Likewise, coenzyme Q is a component of the electron transport chain and is also an important antioxidant, and it is effective in transgenic mouse models of neurodegenerative diseases as well as MPTP and 3-NP. A recent phase III clinical trial in PD was unsuccessful (unpublished work); however, trials in HD and Friedreich's ataxia are continuing. Several compounds have been developed that can specifically target mitochondria. These include compounds such as mitoQ, a form of coenzyme Q linked to triphosphonium ions, which results in selective accumulation within mitochondria. There are also novel peptide antioxidants, termed SS31 and SS20, which bind to the inner mitochondrial membrane, and are neuroprotective in transgenic mouse models of ALS as well as in neurotoxin models (Petri et al., 2006). Dexpramipexole, an isomer of the dopamine agonist pramipexole, accumulates in mitochondria, where it exerts antioxidant effects, and inhibits the activation of the mitochondrial permeability transition. Dexpramipexole has shown efficacy in a phase II clinical trial in ALS, where it produced improvement on the ALS functional rating scale and mortality (Cudkowicz et al., 2011).

Other approaches are to modulate transcription, such as the Nrf2/ARE pathway, which when activated by triterpenoids exerts neuroprotective effects in transgenic mouse models of AD, HD, and ALS, and against MPTP. Dimethylfumarate, another agent that activates this pathway, is protective in multiple sclerosis (Gold et al., 2012). PGC-1 $\alpha$ induces mitochondrial biogenesis and expression of antioxidant enzymes, and we and others have shown that pharmacologic agents that activate PGC- $1 \alpha$ are protective in transgenic mouse models of neurodegenerative diseases including HD, ALS, and A $\beta$ toxicity (Weydt et al., 2006; Qin et al., 2009; Liang et al., 2011; Zhao et al., 2011; Johri et al., 2012). PGC- $1 \alpha$ activity is modulated by SIRT1, an NAD-dependent deacetylase, and activation of SIRT1 is protective in models of HD (Jeong et al., 2012; Jiang et al., 2012). There are therefore a number of promising new compounds and therapeutic targets that modulate mitochondria and produce neuroprotective effects (Fig. 1). These compounds show great promise for treating patients who suffer from neurodegenerative diseases, for which there is as yet no effective treatment to slow or halt the underlying disease processes.

\section{Authorship Contributions} Beal.

Wrote or contributed to the writing of the manuscript: Johri and

\section{References}

Beal MF (2005) Mitochondria take center stage in aging and neurodegeneration. Ann Neurol 58:495-505.

Beal MF (2007) Mitochondria and neurodegeneration. Novartis Found Symp 287: zpg183-192; discussion 192-186.

Beal MF (2009) Therapeutic approaches to mitochondrial dysfunction in Parkinson's disease. Parkinsonism Relat Disord 15 (Suppl 3):S189-S194.

Beal MF (2011) Neuroprotective effects of creatine. Amino Acids 40:1305-1313.

Beal MF, Brouillet E, Jenkins BG, Ferrante RJ, Kowall NW, Miller JM, Storey E, Srivastava R, Rosen BR, and Hyman BT (1993) Neurochemical and histologic characterization of striatal excitotoxic lesions produced by the mitochondrial toxin 3-nitropropionic acid. J Neurosci 13:4181-4192.

Bender A, Krishnan KJ, Morris CM, Taylor GA, Reeve AK, Perry RH, Jaros E, Hersheson JS, Betts J, Klopstock T, et al. (2006) High levels of mitochondrial DNA deletions in substantia nigra neurons in aging and Parkinson disease. Nat Genet 38:515-517.

Bender A, Schwarzkopf RM, McMillan A, Krishnan KJ, Rieder G, Neumann M, Elstner M, Turnbull DM, and Klopstock T (2008) Dopaminergic midbrain neurons are the prime target for mitochondrial DNA deletions. J Neurol 255:1231-1235.

Bosetti F, Brizzi F, Barogi S, Mancuso M, Siciliano G, Tendi EA, Murri L, Rapoport SI, and Solaini G (2002) Cytochrome $c$ oxidase and mitochondrial F1F0-ATPase (ATP synthase) activities in platelets and brain from patients with Alzheimer's disease. Neurobiol Aging 23:371-376.

Bossy-Wetzel E, Petrilli A, and Knott AB (2008) Mutant huntingtin and mitochondrial dysfunction. Trends Neurosci 31:609-616.

Browne SE and Beal MF (2004) The energetics of Huntington's disease. Neurochem Res 29:531-546.

Bubber P, Haroutunian V, Fisch G, Blass JP, and Gibson GE (2005) Mitochondrial abnormalities in Alzheimer brain: mechanistic implications. Ann Neurol 57:695703.

Cantó C, Gerhart-Hines Z, Feige JN, Lagouge M, Noriega L, Milne JC, Elliott PJ, Puigserver P, and Auwerx J (2009) AMPK regulates energy expenditure by modulating NAD + metabolism and SIRT1 activity. Nature 458:1056-1060.

Chaturvedi RK, Adhihetty P, Shukla S, Hennessy T, Calingasan N, Yang L, Starkov A, Kiaei M, Cannella M, Sassone J, et al. (2009) Impaired PGC-1 $\alpha$ function in muscle in Huntington's disease. Hum Mol Genet 18:3048-3065.

Chaturvedi RK and Beal MF (2008) PPAR: a therapeutic target in Parkinson's disease. J Neurochem 106:506-518.

Chaturvedi RK, Calingasan NY, Yang L, Hennessey T, Johri A, and Beal MF (2010) Impairment of PGC-1 $\alpha$ expression, neuropathology and hepatic steatosis in a transgenic mouse model of Huntington's disease following chronic energy deprivation. Hum Mol Genet 19:3190-3205.

Chen H, McCaffery JM, and Chan DC (2007) Mitochondrial fusion protects against neurodegeneration in the cerebellum. Cell 130:548-562.

Chiang MC, Chen CM, Lee MR, Chen HW, Chen HM, Wu YS, Hung CH, Kang JJ, Chang CP, Chang C, et al. (2010) Modulation of energy deficiency in Huntington's disease via activation of the peroxisome proliferator-activated receptor $\gamma$. Hum Mol Genet 19:4043-4058.

Cho DH, Nakamura T, Fang J, Cieplak P, Godzik A, Gu Z, and Lipton SA (2009) S-nitrosylation of Drp1 mediates $\beta$-amyloid-related mitochondrial fission and neuronal injury. Science 324:102-105.

Clark J, Reddy S, Zheng K, Betensky RA, and Simon DK (2011) Association of PGC-1 $\alpha$ polymorphisms with age of onset and risk of Parkinson's disease. BMC Med Genet 12:69.

Coskun PE, Beal MF, and Wallace DC (2004) Alzheimer's brains harbor somatic mtDNA control-region mutations that suppress mitochondrial transcription and replication. Proc Natl Acad Sci U S A 101:10726-10731.

Costa V, Giacomello M, Hudec R, Lopreiato R, Ermak G, Lim D, Malorni W, Davies KJ, Carafoli E, and Scorrano L (2010) Mitochondrial fission and cristae disruption increase the response of cell models of Huntington's disease to apoptotic stimuli. EMBO Mol Med 2:490-503.

Cudkowicz M, Bozik ME, Ingersoll EW, Miller R, Mitsumoto H, Shefner J, Moore DH, Schoenfeld D, Mather JL, Archibald D, et al. (2011) The effects of dexpramipexole (KNS-760704) in individuals with amyotrophic lateral sclerosis. Nat Med 17:1652-1656.

Cui L, Jeong H, Borovecki F, Parkhurst CN, Tanese N, and Krainc D (2006) Transcriptional repression of PGC- $1 \alpha$ by mutant huntingtin leads to mitochondrial dysfunction and neurodegeneration. Cell 127:59-69.

Da Cruz S and Cleveland DW (2011) Understanding the role of TDP-43 and FUS/ TLS in ALS and beyond. Curr Opin Neurobiol 21:904-919.

Da Cruz S, Parone PA, Lopes VS, Lillo C, McAlonis-Downes M, Lee SK, Vetto AP, Petrosyan S, Marsala M, Murphy AN, et al. (2012) Elevated PGC- $1 \alpha$ activity sustains mitochondrial biogenesis and muscle function without extending survival in a mouse model of inherited ALS. Cell Metab 15:778-786.

Davis RE and Williams M (2012) Mitochondrial function and dysfunction: an update. $J$ Pharmacol Exp Ther 342:598-607.

de Calignon A, Polydoro M, Suárez-Calvet M, William C, Adamowicz DH, Kopeikina KJ, Pitstick R, Sahara N, Ashe KH, Carlson GA, et al. (2012) Propagation of $\tau$ pathology in a model of early Alzheimer's disease. Neuron 73:685-697.

De Coo IF, Renier WO, Ruitenbeek W, Ter Laak HJ, Bakker M, Schägger H, Van Oost BA, and Smeets HJ (1999) A 4-base pair deletion in the mitochondrial cytochrome $b$ gene associated with parkinsonism/MELAS overlap syndrome. Ann Neurol 45:130-133.

De Vos KJ, Mórotz GM, Stoica R, Tudor EL, Lau KF, Ackerley S, Warley A, Shaw 
CE, and Miller CC (2012) VAPB interacts with the mitochondrial protein PTPIP51 to regulate calcium homeostasis. Hum Mol Genet 21:1299-1311.

Donmez G, Arun A, Chung CY, McLean PJ, Lindquist S, and Guarente L (2012) SIRT1 protects against $\alpha$-synuclein aggregation by activating molecular chaperones. J Neurosci 32:124-132.

Dumont M, Kipiani K, Yu F, Wille E, Katz M, Calingasan NY, Gouras GK, Lin MT, and Beal MF (2011) Coenzyme Q10 decreases amyloid pathology and improves behavior in a transgenic mouse model of Alzheimer's disease. J Alzheimers Dis 27:211-223.

Ekstrand MI, Terzioglu M, Galter D, Zhu S, Hofstetter C, Lindqvist E, Thams S, Bergstrand A, Hansson FS, Trifunovic A, et al. (2007) Progressive parkinsonism in mice with respiratory-chain-deficient dopamine neurons. Proc Natl Acad Sci U S A 104:1325-1330.

Fulco M, Cen Y, Zhao P, Hoffman EP, McBurney MW, Sauve AA, and Sartorelli V (2008) Glucose restriction inhibits skeletal myoblast differentiation by activating SIRT1 through AMPK-mediated regulation of Nampt. Dev Cell 14:661-673.

Galter D, Pernold K, Yoshitake T, Lindqvist E, Hoffer B, Kehr J, Larsson NG, and Olson L (2010) MitoPark mice mirror the slow progression of key symptoms and -DOPA response in Parkinson's disease. Genes Brain Behav 9:173-181.

Gibson GE, Sheu KF, and Blass JP (1998) Abnormalities of mitochondrial enzymes in Alzheimer disease. J Neural Transm 105:855-870

Gold R, Linker RA, and Stangel M (2012) Fumaric acid and its esters: an emerging treatment for multiple sclerosis with antioxidative mechanism of action. Clin Immunol 142:44-48.

Handschin C and Spiegelman BM (2006) Peroxisome proliferator-activated receptor $\gamma$ coactivator 1 coactivators, energy homeostasis, and metabolism. Endocr Rev 27:728-735.

Harris JA, Devidze N, Verret L, Ho K, Halabisky B, Thwin MT, Kim D, Hamto P, Lo I, Yu GQ, et al. (2010) Transsynaptic progression of amyloid- $\beta$-induced neuronal dysfunction within the entorhinal-hippocampal network. Neuron 68:428-441.

Ho DJ, Calingasan NY, Wille E, Dumont M, and Beal MF (2010) Resveratrol protects against peripheral deficits in a mouse model of Huntington's disease. Exp Neurol 225:74-84.

Igoudjil A, Magrané J, Fischer LR, Kim HJ, Hervias I, Dumont M, Cortez C, Glass JD, Starkov AA, and Manfredi G (2011) In vivo pathogenic role of mutant SOD1 localized in the mitochondrial intermembrane space. J Neurosci 31:15826-15837.

Israelson A, Arbel N, Da Cruz S, Ilieva H, Yamanaka K, Shoshan-Barmatz V, and Cleveland DW (2010) Misfolded mutant SOD1 directly inhibits VDAC1 conductance in a mouse model of inherited ALS. Neuron 67:575-587.

Jeong H, Cohen DE, Cui L, Supinski A, Savas JN, Mazzulli JR, Yates JR, 3rd, Bordone L, Guarente L, et al. (2012) Sirt1 mediates neuroprotection from mutant huntingtin by activation of the TORC 1 and CREB transcriptional pathway. Nat Med 18:159-165

Jiang M, Wang J, Fu J, Du L, Jeong H, West T, Xiang L, Peng Q, Hou Z, Cai H, et al. (2012) Neuroprotective role of Sirt1 in mammalian models of Huntington's disease through activation of multiple Sirt1 targets. Nat Med 18:153-158.

Johri A, Calingasan NY, Hennessey TM, Sharma A, Yang L, Wille E, Chandra A, and Beal MF (2012) Pharmacologic activation of mitochondrial biogenesis exerts widespread beneficial effects in a transgenic mouse model of Huntington's disease. Hum Mol Genet 21:1124-1137.

Johri A, Chaturvedi RK, and Beal MF (2011a) Hugging tight in Huntington's. Nat Med 17:245-246.

Johri A, Starkov AA, Chandra A, Hennessey T, Sharma A, Orobello S, Squitieri F, Yang L, and Beal MF (2011b) Truncated peroxisome proliferator-activated receptor- $\gamma$ coactivator $1 \alpha$ splice variant is severely altered in Huntington's disease. Neurodegener Dis 8:496-503.

Kelly DP and Scarpulla RC (2004) Transcriptional regulatory circuits controlling mitochondrial biogenesis and function. Genes Dev 18:357-368.

Kim D, Nguyen MD, Dobbin MM, Fischer A, Sananbenesi F, Rodgers JT, Delalle I, Baur JA, Sui G, Armour SM, et al. (2007) SIRT1 deacetylase protects against neurodegeneration in models for Alzheimer's disease and amyotrophic lateral sclerosis. EMBO J 26:3169-3179.

Kim J, Moody JP, Edgerly CK, Bordiuk OL, Cormier K, Smith K, Beal MF, and Ferrante RJ (2010) Mitochondrial loss, dysfunction and altered dynamics in Huntington's disease. Hum Mol Genet 19:3919-3935.

Kish SJ, Bergeron C, Rajput A, Dozic S, Mastrogiacomo F, Chang LJ, Wilson JM, DiStefano LM, and Nobrega JN (1992) Brain cytochrome oxidase in Alzheimer's disease. J Neurochem 59:776-779.

Larsson NG, Wang J, Wilhelmsson H, Oldfors A, Rustin P, Lewandoski M, Barsh GS, and Clayton DA (1998) Mitochondrial transcription factor A is necessary for mtDNA maintenance and embryogenesis in mice. Nat Genet 18:231-236.

Leone TC, Lehman JJ, Finck BN, Schaeffer PJ, Wende AR, Boudina S, Courtois M, Wozniak DF, Sambandam N, Bernal-Mizrachi C, et al. (2005) PGC-1 $\alpha$ deficiency causes multi-system energy metabolic derangements: muscle dysfunction, abnormal weight control and hepatic steatosis. PLoS Biol 3:e101.

Liang $\mathrm{H}$ and Ward WF (2006) PGC-1 $\alpha$ : a key regulator of energy metabolism. Adv Physiol Educ 30:145-151.

Liang H, Ward WF, Jang YC, Bhattacharya A, Bokov AF, Li Y, Jernigan A, Richardson A, and Van Remmen H (2011) PGC-1 $\alpha$ protects neurons and alters disease progression in an amyotrophic lateral sclerosis mouse model. Muscle Nerve 44: 947-956.

Lim MA, Selak MA, Xiang Z, Krainc D, Neve RL, Kraemer BC, Watts JL, and Kalb RG (2012) Reduced activity of AMP-activated protein kinase protects against genetic models of motor neuron disease. $J$ Neurosci 32:1123-1141.

Lin J, Handschin C, and Spiegelman BM (2005) Metabolic control through the PGC-1 family of transcription coactivators. Cell Metab 1:361-370.

Lin J, Wu PH, Tarr PT, Lindenberg KS, St-Pierre J, Zhang CY, Mootha VK, Jäger S, Vianna CR, Reznick RM, et al. (2004) Defects in adaptive energy metabolism with CNS-linked hyperactivity in PGC-1 $\alpha$ null mice. Cell 119:121-135.

Luk KC, Kehm VM, Zhang B, O'Brien P, Trojanowski JQ, and Lee VM (2012)
Intracerebral inoculation of pathological $\alpha$-synuclein initiates a rapidly progresive neurodegenerative $\alpha$-synucleinopathy in mice. J Exp Med 209:975-986.

Ma TC, Buescher JL, Oatis B, Funk JA, Nash AJ, Carrier RL, and Hoyt KR (2007) Metformin therapy in a transgenic mouse model of Huntington's disease. Neurosci Lett 411:98-103.

Magrané J and Manfredi G (2009) Mitochondrial function, morphology, and axona transport in amyotrophic lateral sclerosis. Antioxid Redox Signal 11:1615-1626. Magrané J, Sahawneh MA, Przedborski S, Estévez ÁG, and Manfredi G (2012) Mitochondrial dynamics and bioenergetic dysfunction is associated with synaptic alterations in mutant SOD1 motor neurons. J Neurosci 32:229-242.

Manczak M, Calkins MJ, and Reddy PH (2011) Impaired mitochondrial dynamics and abnormal interaction of amyloid $\beta$ with mitochondrial protein Drp1 in neurons from patients with Alzheimer's disease: implications for neuronal damage. Hum Mol Genet 20:2495-2509.

Manczak M, Park BS, Jung Y, and Reddy PH (2004) Differential expression of oxidative phosphorylation genes in patients with Alzheimer's disease: implications for early mitochondrial dysfunction and oxidative damage. Neuromol Med 5:147-162.

Mandrekar-Colucci S and Landreth GE (2011) Nuclear receptors as therapeutic targets for Alzheimer's disease. Expert Opin Ther Targets 15:1085-1097.

Mochel F, Durant B, Meng X, O'Callaghan J, Yu H, Brouillet E, Wheeler VC, Humbert S, Schiffmann R, and Durr A (2012) Early alterations of brain cellular energy homeostasis in Huntington disease models. $J$ Biol Chem 287:1361-1370.

Mudò G, Mäkelä J, Di Liberto V, Tselykh TV, Olivieri M, Piepponen P, Eriksson O, Mälkiä A, Bonomo A, Kairisalo M, et al. (2012) Transgenic expression and activation of PGC-1alpha protect dopaminergic neurons in the MPTP mouse model of Parkinson's disease. Cell Mol Life Sci 69:1153-1165.

Narendra DP and Youle RJ (2011) Targeting mitochondrial dysfunction: role for PINK1 and Parkin in mitochondrial quality control. Antioxid Redox Signal 14 1929-1938.

Niu J, Yu M, Wang C, and Xu Z (2012) Leucine-rich repeat kinase 2 (LRRK2) disturbs mitochondrial dynamics via dynamin-Like protein (DLP1). J Neurochem http://dx.doi.org/10.1111/j.1471-4159.2012.07809.x.

Park SJ, Ahmad F, Philp A, Baar K, Williams T, Luo H, Ke H, Rehmann H, Taussig R, Brown AL, et al. (2012) Resveratrol ameliorates aging-related metabolic phenotypes by inhibiting cAMP phosphodiesterases. Cell 148:421-433.

Parker WD Jr and Parks JK (2005) Mitochondrial ND5 mutations in idiopathic Parkinson's disease. Biochem Biophys Res Commun 326:667-669.

Petri S, Kiaei M, Damiano M, Hiller A, Wille E, Manfredi G, Calingasan NY, Szeto $\mathrm{HH}$, and Beal MF (2006) Cell-permeable peptide antioxidants as a novel therapeutic approach in a mouse model of amyotrophic lateral sclerosis. J Neurochem 98:1141-1148.

Price NL, Gomes AP, Ling AJ, Duarte FV, Martin-Montalvo A, North BJ, Agarwal B, Ye L, Ramadori G, Teodoro JS, et al. (2012) SIRT1 is required for AMPK activation and the beneficial effects of resveratrol on mitochondrial function. Cell Metab 15:675-690.

Prusiner SB (1998) Prions. Proc Nat Acad Sci U S A 95:13363-13383.

Puigserver P and Spiegelman BM (2003) Peroxisome proliferator-activated recep tor- $\gamma$ coactivator $1 \alpha$ (PGC-1 $\alpha)$ : transcriptional coactivator and metabolic regulator. Endocr Rev 24:78-90.

Qin W, Haroutunian V, Katsel P, Cardozo CP, Ho L, Buxbaum JD, and Pasinetti GM (2009) PGC-1 $\alpha$ expression decreases in the Alzheimer disease brain as a function of dementia. Arch Neurol 66:352-361.

Quintanilla RA, Jin YN, Fuenzalida K, Bronfman M, and Johnson GV (2008) Rosiglitazone treatment prevents mitochondrial dysfunction in mutant huntingtinexpressing cells: possible role of peroxisome proliferator-activated receptor- $\gamma$ $(\mathrm{PPAR} \gamma)$ in the pathogenesis of Huntington disease. J Biol Chem 283:2562825637.

Reddy PH, Mao P, and Manczak M (2009) Mitochondrial structural and functional dynamics in Huntington's disease. Brain Res Rev 61:33-48.

Reddy PH, Reddy TP, Manczak M, Calkins MJ, Shirendeb U, and Mao P (2011) Dynamin-related protein 1 and mitochondrial fragmentation in neurodegenerative diseases. Brain Res Rev 67:103-118.

Reeve AK, Krishnan KJ, Elson JL, Morris CM, Bender A, Lightowlers RN, and Turnbull DM (2008) Nature of mitochondrial DNA deletions in substantia nigra neurons. Am J Hum Genet 82:228-235.

Sheng B, Wang X, Su B, Lee HG, Casadesus G, Perry G, and Zhu X (2012) Impaired mitochondrial biogenesis contributes to mitochondrial dysfunction in Alzheimer's disease. J Neurochem 120:419-429.

Shin JH, Ko HS, Kang H, Lee Y, Lee YI, Pletinkova O, Troconso JC, Dawson VL, and Dawson TM (2011) PARIS (ZNF746) repression of PGC-1 $\alpha$ contributes to neurodegeneration in Parkinson's disease. Cell 144:689-702.

Shirendeb U, Reddy AP, Manczak M, Calkins MJ, Mao P, Tagle DA, and Reddy PH (2011) Abnormal mitochondrial dynamics, mitochondrial loss and mutant huntingtin oligomers in Huntington's disease: implications for selective neuronal damage. Hum Mol Genet 20:1438-1455.

Smigrodzki R, Parks J, and Parker WD (2004) High frequency of mitochondrial complex I mutations in Parkinson's disease and aging. Neurobiol Aging 25:1273-1281.

Song W, Chen J, Petrilli A, Liot G, Klinglmayr E, Zhou Y, Poquiz P, Tjong J, Pouladi MA, Hayden MR, et al. (2011) Mutant huntingtin binds the mitochondrial fission GTPase dynamin-related protein-1 and increases its enzymatic activity. Nat Med 17:377-382

St-Pierre J, Drori S, Uldry M, Silvaggi JM, Rhee J, Jäger S, Handschin C, Zheng K, Lin J, Yang W, et al. (2006) Suppression of reactive oxygen species and neurodegeneration by the PGC-1 transcriptional coactivators. Cell 127:397-408.

Swerdlow RH, Burns JM, and Khan SM (2010) The Alzheimer's disease mitochondrial cascade hypothesis. J Alzheimers Dis 20 (Suppl 2):S265-S279.

Taherzadeh-Fard E, Saft C, Andrich J, Wieczorek S, and Arning L (2009) PGC-1 $\alpha$ as modifier of onset age in Huntington disease. Mol Neurodegener 4:10.

Um JH, Park SJ, Kang H, Yang S, Foretz M, McBurney MW, Kim MK, Viollet B, and 
Chung JH (2010) AMP-activated protein kinase-deficient mice are resistant to the metabolic effects of resveratrol. Diabetes 59:554-563.

Vande Velde C, McDonald KK, Boukhedimi Y, McAlonis-Downes M, Lobsiger CS, Bel Hadj S, Zandona A, Julien JP, Shah SB, and Cleveland DW (2011) Misfolded SOD1 associated with motor neuron mitochondria alters mitochondrial shape and distribution prior to clinical onset. PLoS One 6:e22031.

Wang X, Winter D, Ashrafi G, Schlehe J, Wong YL, Selkoe D, Rice S, Steen J, LaVoie MJ, and Schwarz TL (2011) PINK1 and Parkin target Miro for phosphorylation and degradation to arrest mitochondrial motility. Cell 147:893-906.

Weydt P, Pineda VV, Torrence AE, Libby RT, Satterfield TF, Lazarowski ER, Gilbert ML, Morton GJ, Bammler TK, Strand AD, et al. (2006) Thermoregulatory and metabolic defects in Huntington's disease transgenic mice implicate PGC- $1 \alpha$ in Huntington's disease neurodegeneration. Cell Metab 4:349-362.

Weydt P, Soyal SM, Gellera C, Didonato S, Weidinger C, Oberkofler H, Landwehrmeyer GB, and Patsch W (2009) The gene coding for PGC-1 $\alpha$ modifies age at onset in Huntington's Disease. Mol Neurodegener 4:3.

Xiang Z, Valenza M, Cui L, Leoni V, Jeong HK, Brilli E, Zhang J, Peng Q, Duan W, Reeves SA, et al. (2011) Peroxisome-proliferator-activated receptor $\gamma$ coactivator $1 \alpha$ contributes to dysmyelination in experimental models of Huntington's disease. $J$ Neurosci 31:9544-9553.

Yang L, Calingasan NY, Thomas B, Chaturvedi RK, Kiaei M, Wille EJ, Liby KT,
Williams C, Royce D, Risingsong R, et al. (2009a) Neuroprotective effects of the triterpenoid, CDDO methyl amide, a potent inducer of Nrf2-mediated transcription. PLoS One 4:e5757.

Yang L, Calingasan NY, Wille EJ, Cormier K, Smith K, Ferrante RJ, and Beal MF (2009b) Combination therapy with coenzyme Q10 and creatine produces additive neuroprotective effects in models of Parkinson's and Huntington's diseases. J Neurochem 109:1427-1439.

Zhang SF, Hennessey T, Yang L, Starkova NN, Beal MF, and Starkov AA (2011) Impaired brain creatine kinase activity in Huntington's disease. Neurodegener Dis 8:194-201.

Zhao W, Varghese M, Yemul S, Pan Y, Cheng A, Marano P, Hassan S, Vempati P, Chen F, Qian X, et al. (2011) Peroxisome proliferator activator receptor $\gamma$ coactivator-1 $\alpha$ (PGC-1 $\alpha$ ) improves motor performance and survival in a mouse model of amyotrophic lateral sclerosis. Mol Neurodegener 6:51.

Zheng B, Liao Z, Locascio JJ, Lesniak KA, Roderick SS, Watt ML, Eklund AC, Zhang-James Y, Kim PD, Hauser MA, et al. (2010) PGC-1 $\alpha$, a potential therapeutic target for early intervention in Parkinson's disease. Sci Transl Med 2:52ra73.

Address correspondence to. Dr. M. Flint Beal, Department of Neurology and Neuroscience, Weill Medical College of Cornell University, 525 East 68th Street, F610, New York, NY 10065. E-mail: fbeal@med.cornell.edu 